vol.4 No.1 - 2017

\title{
CRITICAL CARE NURSES KNOWLEDGE AND PRACTICES REGARDING WEANING OF PATIENTS FROM MECHANICAL VENTILATION \\ ${ }^{1}$ Jasim Mohammed Khalaf, ${ }^{2}$ Amal RashadRiad, ${ }^{3}$ Shaimaa Ahmed Awad \\ 1 Critical Care and Emergency Nursing, Faculty of Nursing, MansouraUniversity \\ 2Anaesthesia and Surgical Intensive Care, Faculty of Medicine, MansouraUniversity. \\ 3 Critical Care and Emergency Nursing, Faculty of Nursing, MansouraUniversity jasimkhalaf47@yahoo.com
}

\begin{abstract}
Background: Many patients require admission to Intensive Care Unit (ICU). As many as $30 \%$ of admissions, and $90 \%$ of all critically ill patients will require at least a short period of MV. There are many risks and complications associated with prolonged MV. To minimize these risks and complications it is important that patients be weaned and extubated from MV at the earliest possible time. However, just as delayed weaning and extubation carries the risk of complications, premature extubation and subsequent reintubation should be avoided where possible,. Weaning is the transition from ventilatory support to spontaneous breathing and can often be achieved easily, but may be difficult in up to $25 \%$ of patients. Numerous studies have shown the benefit of know level of critical care nurses knowledge and practices regarding weaning of patients from mechanical ventilation, for effective participation in weaning process and decreasing MV days and costs. Aim of this study: The aim of this study is to assess the critical care nurses knowledge and practices regarding weaning of patients from mechanical ventilation. Research design: A descriptive design was utilized in this study . Sample: A Convenience sample of that including 50 ICU nurses was recruited in the current study . Setting: The study was conducted at the Intensive Care Units at Emergency Hospital, Mansoura University. Tools of data collection: Two tools were utilized, tested for clarity and viability, and then used to collect data pertinent to the current: Tool I: Structure interviewer questionnaire to assess critical care nurses knowledge regarding weaning of patients from mechanical ventilation. Tool II: Critical Care Nurses practices Observational check list regarding weaning of patients from mechanical ventilation. Results: The current study revealed that, approximately two-third (67\%) of the studied sample had unsatisfactory knowledge level $(<75 \%)$ with a mean total knowledge score of $(43.8 \pm 7.9)$. As well as, majority of studied sample $(97 \%)$ had unsatisfactory performance level $(<75 \%)$ with a mean total performance score of $(59.6 \pm 5.7)$. Negative correlation between mean knowledge scores and mean practice scores; $(r=0.1$ at $\mathrm{p}=0.5)$.Conclusion: Based on the findings of the current study, it can be concluded that Critical care nurses had unsatisfactory knowledge and practices score regarding weaning of patients from mechanical ventilation. Recommendations: Provide nurses with continuous educational programs with evidence based guidelines to improve their knowledge and practices regarding weaning of patients from mechanical ventilation, Follow up nurses' practices in relation mechanical ventilation weaning, Provide nurses with periodic sessions to improve their practices regarding weaning of patients from mechanical ventilation, Establish collaborative interaction between nurses and other health team members as they are working in a multi-disciplinary system to improve the health services provided to patients with mechanical ventilation.
\end{abstract}

Key words: Mechanical ventilation, Weaning, knowledge, practice, critical care nurses 


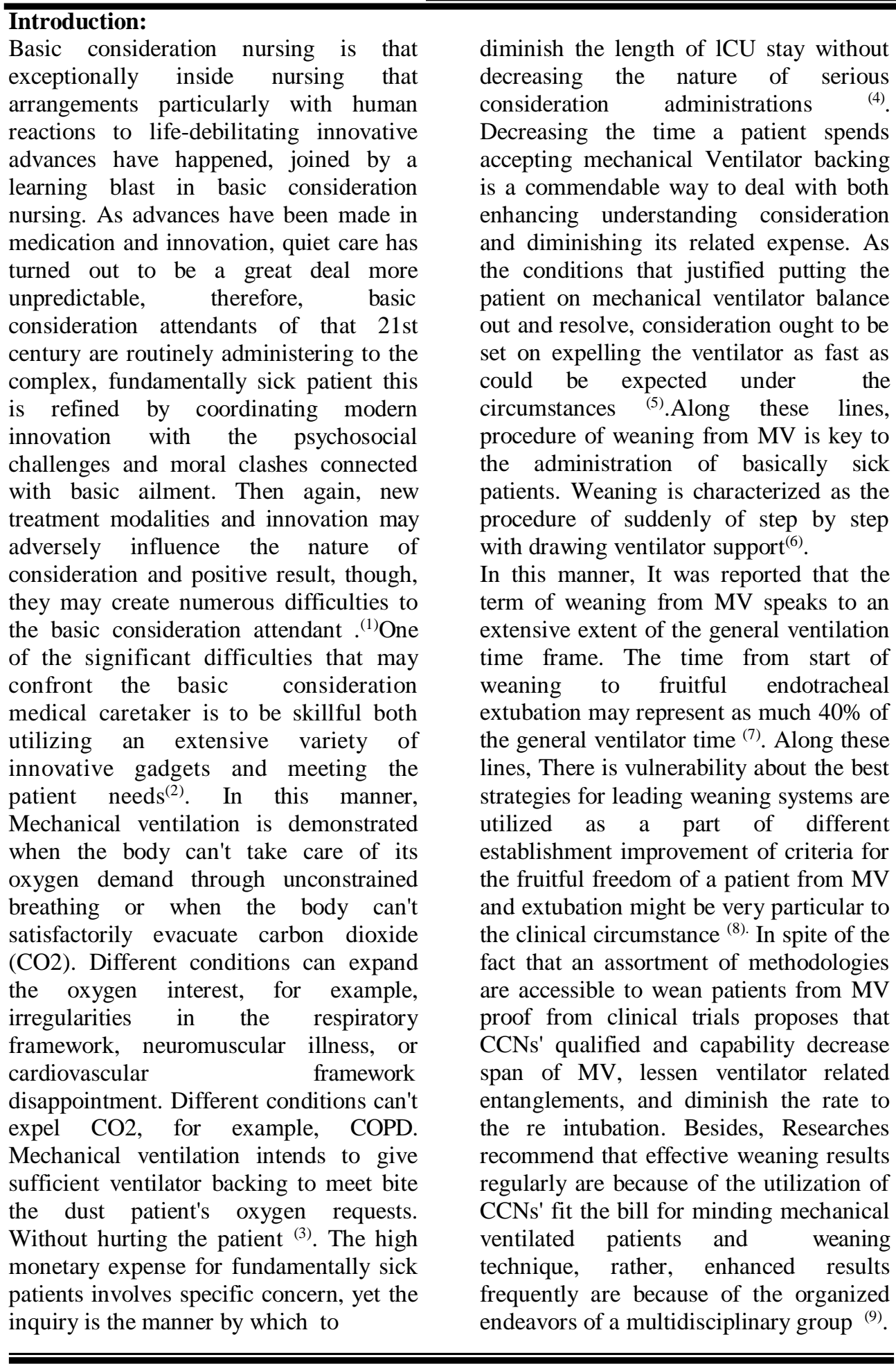


CRITICAL CARE NURSES KNOWLEDGE AND PRACTICES etc..

Along these lines, Critical consideration nursing today needs to characterize essential nursing skill and capability. These levels are required to characterize what constitutes safe practice, as well as to guide medical attendant's basic leadership ${ }^{(10}$. Great CCNs' information and experience can change the procedure of mechanical ventilation weaning and enhance patients' results ${ }^{(11)}$. There is clear proof that weaning rules and conventions coordinated by (CCNs') qualified and respiratory consideration staff can assist the suspension of MV, subsequently improve basic results and lessen costs for fundamentally sick patients ${ }^{(12)}$.Moreover (CCNs') qualified can be give minding to mechanical ventilated patients basic consideration medical attendants with moment, access to weaning procedures and data that encourage prompt basic leadership and take out deferrals. This thusly, spares profitable time and money related assets (13). Subsequently, this study was directed to assess the basic care medical attendants' information and works on with respect to weaning of patients from mechanically ventilation.

\section{Research Hypothesis}

What is the level of knowledge that the critical care nurses' have regarding weaning of patients from mechanical ventilation?

What is the level of practice that the critical care nurses' have regarding weaning of patients from mechanical ventilation?

\section{Subjects and Method}

Study design: An unmistakable exploratory examination configuration was utilized to lead this study. An unmistakable exploration configuration is one in which data is gathered without changing the earth (i.e., nothing is controlled). Here and there these are alluded to as " correlation" or " observational" studies. The workplace of Human Research securities (OHRP) characterizes an elucidating plan as " any outline that is not really exploratory. " in human research, an illustrative outline can give data about the normally happening wellbeing status, conduct, mentalities or different qualities of a specific gathering. Setting: This study was conducted in the Intensive Care Units (ICUs) of Mansoura Emergency Hospital. It encompassed three units with 8 beds in each unit.

Subjects: An accommodation test of 50 medical caretakers' who had no less than one year of experience, required in giving direct care to basically sick patients. Willing to partake intentionally and gave assents were selected.

Tools: Two tools were developed by the investigator based on review of the related literature and used to collect necessary data about the study subjects.

Tool I: "Critical care nurses' knowledge regarding weaning of patients from mechanical ventilation:This tool was developed by the researcher after reviewing the recent related literature, to assess Critical Care Nurses' (CCNs') knowledge regarding weaning of patients from mechanical ventilation.

Scoring system: Scoring system: each right answer got (1). The scores obtained for each set of questions was summed up to get the total score for CCNs' knowledge. The total score was computed out of $63(100 \%)$ classified into two categories as follow unsatisfactory knowledge level $<75 \%$. Satisfactory knowledge level $\geq 75 \%{ }^{(14)}$.

Tool II: "Critical Care Nurses practices Observational check list regarding weaning of patients from mechanical ventilation "

This tool was developed by the researcher after reviewing the recent related literature to assess Critical Care Nurses' (CCNs') practice regarding weaning of patients from mechanical ventilation Scoring system : each item scored on the bases of " Done" or " Not done", done 
scored (1 point) . not done scored (zero). The scores obtained for each set of items were summed up to get the total score for CCNs' practice. Total scoring was classified into two categories as follow: unsatisfactory practice level $<75 \%$, satisfactory practice level $75 \%{ }^{(14)}$.

Methods: An official permission to conduct the proposed study was obtained from the Ethical committee of faculty of Nursing. Mansoura University and the hospital director. Participation in his study was voluntary: each potential subject was informed about the purpose, procedure, benefits, and nature of the study. Participants were assured that they have the right to with draw from the study at any time without any rationale then written consents were obtained. Participants were informed that the obtained data will not be included in any further researches without second consent. Confidentiality and anonymity of each participant were assured through coding of all data and all information has taken was protected and did not affect their annual appraisal. Tools were tested for content related validity by 6 experts in the field of Critical Care \& Emergency Nursing and Medicine from the faculties of Nursing and Medicine : one professors in Intensive care Medicine, Faculty of Medicine, Mansoura University: one professor and four assistant professors from Critical Care and Emergency Nursing department, Faculty of Nursing, Mansoura University. The overall reliability of the tools was tested using (a) cronbach test on a sample of 20 subjects and found to be knowledge and practice. A pilot study was carried out before starting data collection on five nurses $(10 \%)$ to test clarity, feasibility, applicability of the tools and time frame to answer the questionnaire, based on the findings necessary modifications were done accordingly, those nurses were excluded from the study. Assessment of
CCNs' practice observational checklist regarding weaning of patients from mechanical ventilation. was done through indirect observation method using tool II, and was done for three times in different shifts ( morning, afternoon and night shifts) for each nurse participated ; First assessment, second assessment and third assessment were stemmed up to get the mean assessment score. CCNs' knowledge regarding weaning of patients from mechanical ventilation was assessed using self administered tool I questionnaire; the time average for completing the questionnaire ranged from 30- 35 minutes. After the data was collected and transferred into special design formats so as to be suitable for computer feeding. Data was analyzed using a personal computer with statistical package for social sciences (SPSS)

Preparation phase :

Tool I:Critical Care Nurses' knowledge questionnaire regarding weaning of patients from mechanical ventilation. This tool was developed into simple Arabic language by the researcher after reviewing of recent literature.

Tool II: Critical Care Nurses' practice observational checklist regarding weaning of patients from mechanical ventilation, was modified by the researcher to be suitable for the study after reviewing recent literature. Tools were tested for content related validity by 6 experts in the field of Critical Care \& Emergency Nursing and Medicine from the faculties of Nursing and Medicine : one professors in Intensive care Medicine, Faculty of Medicine, Mansoura University: one professor and four assistant professors from Critical Care and Emergency Nursing department, Faculty of Nursing, Mansoura University . The overall reliability of the tools was tested using (a) cronbach test on a sample of 20 subjects and found to be knowledge and practice. 
CRITICAL CARE NURSES KNOWLEDGE AND PRACTICES etc...

Results:

Part I Part I: Is concerned with answers of the first stated research question (tables 1 to 3). The first stated research question was: what is the level of knowledge that the critical care nurses' have regarding weaning of patients from mechanical ventilation?

Table1 :Shows that most of the studied nurses' (82\%, 76\% and 74\%) have got (incorrect) answers regarding information of mechanical ventilation as a medical symbol SaO2.A medical symbol $\mathrm{Pao} 2$ and a medical symbol Paco2 respectively.

On the other hand, (74\% and 70\%) of the studied subjects have got (correct) answers that related to characteristic of respiratory failure and the uses of mechanical ventilation respectively

Table (1): Percentage distribution of nurses' knowledge regarding information of mechanical ventilation $(n=50)$

\begin{tabular}{|l|r|r|r|r|}
\hline \multicolumn{2}{|c|}{ Question items regarding information of MV } & \multicolumn{2}{|c|}{ Done } & \multicolumn{2}{|c|}{ Not done } \\
\cline { 2 - 5 } & $\mathbf{N}$. & $\mathbf{( \% )}$ & $\mathbf{N}$. & $\mathbf{( \% )}$ \\
\hline 1-It is used to ventilate the lungs artificially & 37 & 74 & 13 & 26 \\
\hline 2-It is failure to take oxygen and eliminate carbon dioxide & 35 & 70 & 15 & 30 \\
\hline 3-A medical symbol Pao2 (80-100 mm Hg). & 12 & 24 & 38 & 76 \\
\hline 4- A medical symbol Paco2 (35-45 mm Hg). & 13 & 26 & 37 & 74 \\
\hline 5 A medical symbol Sao2(95\%-100\%). & 9 & 18 & 41 & 82 \\
\hline 6 A medical symbol PH (7.35-7.45 ). & 20 & 40 & 30 & 60 \\
\hline
\end{tabular}

Table 2:. Shows that the majority of the studied subjects $(82 \%, 78 \%$ and $74 \%)$ have got incorrect answers regarding criteria need for MV such as respiratory rate (RR) value. Indicators of arterial blood (ABG) needed to put the patient on MV and tidal volume (VT) value respectively.

Table (2): Distribution of nurses' knowledge regarding criteria needed for mechanical ventilator $(n=50)$.

\begin{tabular}{|l|r|r|r|r|}
\hline \multicolumn{1}{|c|}{$\begin{array}{c}\text { Question items regarding criteria needed for } \\
\text { MV }\end{array}$} & \multicolumn{2}{c|}{$\begin{array}{c}\text { Correct } \\
\text { answers }\end{array}$} & \multicolumn{2}{c|}{$\begin{array}{c}\text { Incorrect } \\
\text { answers }\end{array}$} \\
\cline { 2 - 5 } & $\mathbf{N}$ & $\mathbf{( \% )}$ & \multicolumn{1}{c|}{ N. } & \multicolumn{1}{c|}{ (\%) } \\
\hline 7-Respiratory rate (RR) per minute is ---- & 9 & 18 & 41 & 82 \\
\hline 8- Tidal volume (VT) ml/kg is ----- & 13 & 26 & 37 & 74 \\
\hline $\begin{array}{l}\text { 9-Indicators needed to put the patient on a MV } \\
\text { when arterial blood (ABG) are }\end{array}$ & 11 & 22 & 39 & 78 \\
\hline
\end{tabular}

Table3 : Shows that the majority of studied nurses' $(80 \%, 80 \%$ and $70 \%)$ have got (incorrect) answers regarding weaning from mechanical ventilation as the Rapid Shallow Breathing Index (RSBI) value in the first of Spontaneous Breathing Trial (SBT). The Continuous Positive Airway Pressure (CPAP) value in the advance stage of Spontaneous Breathing Trial (SBT) and the time of weaning process respectively. 
Jasim Mohammed Khalaf et. al.

Table (3) : Distribution of nurses' knowledge regarding weaning from mechanical ventilation $(n=50)$

\begin{tabular}{|l|r|r|r|r|}
\hline \multicolumn{1}{|c|}{ Question items regarding weaning from MV } & \multicolumn{2}{|c|}{$\begin{array}{c}\text { Correct } \\
\text { answers }\end{array}$} & \multicolumn{2}{c|}{$\begin{array}{c}\text { Incorrect } \\
\text { answers }\end{array}$} \\
\hline & N. & $\mathbf{( \% )}$ & N. & $(\%)$ \\
\hline 10-Weaning process parts include & 20 & 40 & 30 & 60 \\
\hline 11-The position of patient in the case of weaning & 20 & 40 & 30 & 60 \\
\hline 12-The time of weaning process & 15 & 30 & 35 & 70 \\
\hline $\begin{array}{l}\text { 13-The Rapid Shallow Breathing Index (RSBI) value } \\
\text { in the first of Spontaneous Breathing Trial (SBT) }\end{array}$ & 10 & 20 & 40 & 80 \\
\hline $\begin{array}{l}\text { 14-The Continuous Positive Airway Pressure (CPAP) } \\
\text { value in the advance stage of Spontaneous Breathing } \\
\text { Trial (SBT) }\end{array}$ & 10 & 20 & 40 & 80 \\
\hline
\end{tabular}

Part II: Is concerned with answers of the second research question (tables 4 and5). The second stated research question was: what is the level of practice that the critical care nurses' have regarding weaning of patients from mechanical ventilation?

Table 4: Shows that most of the studied nurses' ( $90 \%, 82 \%$ and $78 \%$ ) of the nurses didn't explain procedure to patient. Assess minute volume and assess respiratory rate respectively.

While, the majority of the nurses' $(86 \%, 82 \%$ \& $78 \%)$ maintain position (bed head 30-40 degree) and patency of airway. Assess peak pressure and assess flow rate respectively.

Table (4): Distribution of nurses' practice regarding ventilator parameters $(n=50)$.

\begin{tabular}{|l|r|r|r|r|}
\hline \multirow{2}{*}{$\begin{array}{c}\text { Criteria for ventilator parameters checklist weaning } \\
\text { from MV }\end{array}$} & \multicolumn{2}{|c|}{ Done } & \multicolumn{2}{c|}{ Not done } \\
\cline { 2 - 5 } & N. & (\%) & N. & (\%) \\
\hline $\begin{array}{l}\text { 1. Maintain position (bed head 30-40 degree) and } \\
\text { patency of airway }\end{array}$ & 43 & 86 & 7 & 14 \\
\hline 2. Explain procedure to patient. & & & & \\
\hline 3. Monitor vital signs every hour & 14 & 28 & 36 & 72 \\
\hline 4. Assess respiratory rate & 11 & 22 & 39 & 78 \\
\hline 5. Assess tidal volume & 12 & 24 & 38 & 76 \\
\hline 6. Assess fractional of inspired oxygen & 15 & 30 & 35 & 70 \\
\hline 7. Assess inspiratory expiratory ratio & 32 & 64 & 18 & 36 \\
\hline 8. Assess peak pressure & 41 & 82 & 9 & 18 \\
\hline 9. Assess positive end expiratory pressure & 37 & 74 & 13 & 26 \\
\hline 10. Assess flow rate & 39 & 78 & 11 & 22 \\
\hline 11. Assess minute volume & 9 & 18 & 41 & 82 \\
\hline
\end{tabular}

Table5: Shows the most of the studied subject ( $90 \%, 86 \%, 86 \%, 80 \%$ and $80 \%)$ didn't explain procedure to the patient. Discuss the assessment of findings and weaning parameters. Obtain base lines vital signs. Plan to initiate early weaning process in the day and document the patient response or not to the weaning process respectively. 
CRITICAL CARE NURSES KNOWLEDGE AND PRACTICES etc...

On the other hand the majority of the studied subject $(76 \%, 72 \%$ and $70 \%)$ such as assess for weaning under physician orders. Suction when necessary and administer bronchodilator as ordered and terminating weaning when the patient exhibit signs of respiratory distress under respectively.

Table (5): Distribution of nurses' practices regarding readiness for weaning $(n=50)$.

\begin{tabular}{|c|c|c|c|c|}
\hline \multirow[t]{2}{*}{ Readiness For Weaning } & \multicolumn{2}{|c|}{ Done } & \multicolumn{2}{|c|}{ Not done } \\
\hline & $\mathbf{N}$. & $(\%)$ & $\mathbf{N}$. & $(\%)$ \\
\hline $\begin{array}{l}\text { 1- Assess for } \\
\text { - } \quad \text { respiratory status } \\
\text { - } \text { ability to cough and expectorant secretion } \\
\text { - } \text { laboratory data } \\
\text { - } \text { nital signs } \\
\text { - level of consciousness and motivation to wean } \\
\text { optimize patient condition in relation to pain , fatigue } \\
\text { and other medical Conditions which could affect } \\
\text { weaning }\end{array}$ & 38 & 76 & 12 & 24 \\
\hline $\begin{array}{l}\text { 2-Discuss the assessment of findings and weaning } \\
\text { parameters. }\end{array}$ & 7 & 14 & 43 & 86 \\
\hline 3- Explain procedure to the patient. & 5 & 10 & 45 & 90 \\
\hline 4- Plan to initiate early weaning process in the day. & 10 & 20 & 40 & 80 \\
\hline 5-Obtain base lines vital signs & 7 & 14 & 43 & 86 \\
\hline $\begin{array}{l}\text { 6- Initiate weaning according to the physician orders (T- } \\
\text { piece or PSV). }\end{array}$ & 25 & 50 & 25 & 50 \\
\hline $\begin{array}{l}\text { 7- Suction when necessary and administer } \\
\text { bronchodilator as ordered. }\end{array}$ & 36 & 72 & 14 & 28 \\
\hline $\begin{array}{l}\text { 8- Provide support to the patient and encourage the } \\
\text { patient to breathe normally. }\end{array}$ & 29 & 58 & 21 & 42 \\
\hline $\begin{array}{l}\text { 9- Monitor and documents objective and subjective } \\
\text { findings. }\end{array}$ & 13 & 46 & 37 & 74 \\
\hline $\begin{array}{l}\text { 10- Terminating weaning when the patient exhibit signs } \\
\text { of respiratory distress }\end{array}$ & 35 & 70 & 15 & 30 \\
\hline 11- Lists indicators of respiratory distress & 14 & 28 & 36 & 72 \\
\hline $\begin{array}{l}\text { 12- Document the patient responses or not to the } \\
\text { weaning process. }\end{array}$ & 10 & 20 & 40 & 80 \\
\hline
\end{tabular}

\section{Discussion:}

The consideration of the mechanically ventilated patient is at the center of a basic consideration clinical practice and weaning patients from mechanical ventilator bolster remains a huge test for basic consideration attendants ${ }^{(15)}$ The move to unsupported breathing is regularly intricate procedure, requiring gifted evaluation and arranging by a multidisciplinary group. Along these lines, the utilization of a communitarian 
approach, in which basic leadership is shared among individuals, appears a sensible administration methodology ${ }^{(16)}$.

In the flow examine the discoveries information that addressed the primary exploration question about basic care attendants' learning with respect to weaning of patients from mechanical ventilation "what is the level of information that the basic care medical attendants' have in regards to weaning of patients from mechanical ventilation?" uncovered that lion's share of the concentrated on subjects have unsuitable learning level .

This findings study supported by Kevin T. Martin (2009) ${ }^{(17)}$ which revealed that the $\mathrm{CCNs}$ ' unsatisfactory knowledge level due to many reasons might be is that the curriculum did not focus on the care of patients in critical care, especially in mechanically ventilated patients.

Also, this findings study supported by Hansen, B. S., \& Severinsson, E. (2007) ${ }^{(18)}$ which demonstrate that the comprehensive nature of the four year training course for nurses, with its focus on primary health care, suggests that these nurses do not have an orientation towards intensive care nursing, and most likely will knowledge and practice outside their scope of knowledge and practice and be incompetent within the ICU area.

Moreover, another study by Martin J. Tobin (2001) ${ }^{(19)}$ emphasized that the nurse who cares for the mechanically ventilated patient must demonstrate competence in order to be able to recognise adverse events which may occur, and carry out the necessary interventions which may prevent the patient from moving forward to the ultimate goal of liberation from the ventilator. In spite of potential life threatening complications, mechanical ventilation remains the most common therapeutic modality undertaken in intensive care units.
Likewise, the analyst deciphered the reasons that may have pertinence to the absence of information with respect to weaning of patients from mechanical ventilation related to the instructive level at the specialized BSe Nurses specialized Diploma Nurses, Secondary school Diploma Nurses and what's more, to trouble talking and comprehension of the therapeutic and specialized phrasing in regards to mechanical ventilated patient.

Furthermore, to the few number of CCNs' and increase the number of mechanical ventilated patients follow hard work in the care and monitoring of mechanical ventilation patients, which could lead to negative results and increase the incidence of disease and death.

As regards table (1)conveyance of right and mistaken answers identified with learning sub-things questions concerning data of mechanical ventilation uncovered that, most of the contemplated test have inaccurate answers in inquiries identified with to medical symbol $\mathrm{SaO} 2$.A medical symbol $\mathrm{Pao} 2$ and a medical symbol Paco2 respectively.

This findings study agree with Lanken and colleagues $(\mathbf{2 0 1 3})^{(20)}$ which revealed that nurses who work in ICUs' and care for the mechanically ventilated patients may not be qualified in intensive care nursing ( With the end goal of this study an ICU qualified nurse refers to a registered nurse who has an additional qualification in intensive care nursing) therefore, they may not be competent to care for the automatically ventilated patients (For the purpose of this study competence is used to inform the level of competence indicator of $75 \%$ or more. Competence refers to the nurses' understanding knowledge and thinking which informs the actions the nurse takes. So, competence can be classified in two ways. Firstly, formal competence is when a nurse is assumed to be competent due to 
CRITICAL CARE NURSES KNOWLEDGE AND PRACTICES etc...

her qualifications and the specific duties she can perform. Secondly, and more importantly, genuine capability is characterized as the capacity to apply information to clinical circumstances, practice and utilize aptitudes securely, and show dispositions suitable to the particular patient. Capability in this study alludes to both formal and genuine skills (21). Since educational modules crevices amid preparing, absence of subsidizing for sorting out, general workshops and negative state of mind of basic consideration medical caretakers whereby new data learned at workshops was not promptly connected in clinical information and practice.

This in the streak with study by Girard, et al ., (2008), ${ }^{(22)}$ which revealed, that the CCNs' with lack of knowledge and experience results inappropriate ventilator settings, failure by the nurse to recognize deteriorating in lung function and complications can lead to ventilator initiated lung harm, which may exacerbate the initial pathology of the lungs and this can lead to complications such as pneumothorax, tracheal necrosis, and ventilator associated pneumonia ,these complications can at best prolong the hospital stay of the patient, thereby significantly increasing costs, and at worst lead to increased morbidity and mortality of the patient. Furthermore, The multiple complications and risks associated with intubation and MV increase over time

This findings study agree with Lanken and colleagues $(\mathbf{2 0 1 3})^{(20)}$ which revealed that nurses who work in ICUs' and care for the mechanically ventilated patients may not be qualified in intensive care nursing (For the purpose of this study an ICU qualified nurse refers to a registered nurse who has an additional qualification in intensive care nursing) therefore, they may not be competent to care for the automatically ventilated patients (For the motivation behind this study competence is used to inform the level of competence indicator of $75 \%$ or more. Competence refers to the nurses' understanding knowledge and thinking which informs the actions the nurse takes .

So, competence can be classified in two ways. Firstly, formal competence is when a nurse is assumed to be competent due to her qualifications and the specific duties she can perform. Secondly, and more importantly, real competence is defined as the capacity to apply information to clinical circumstances, practice and utilize abilities securely, and exhibit mentalities fitting to the particular patient. Capability in this study alludes to both formal and genuine skills (Hansen, B. S., \& Severinsson, E. 2007) ${ }^{(18)}$

Because educational programs holes amid preparing, absence of subsidizing for arranging, standard workshops and negative disposition of basic consideration medical caretakers whereby new data learned at workshops was not promptly connected in clinical information and practice.

This is in the same way with study by Girard, et al ., (2008) ${ }^{(22)}$ which revealed, that the CCNs' with lack of knowledge and experience results inappropriate ventilator settings, failure by the nurse to recognize deteriorating in lung function and complications can lead to ventilator incited lung harm, which may exacerbate the initial pathology of the lungs and this can lead to complications such as pneumothorax, tracheal necrosis, and ventilator associated pneumonia .These complications can at best prolong the hospital stay of the patient, thereby significantly increasing costs, and at worst lead to increased morbidity and mortality of the patient. Furthermore, The multiple complications and risks associated with intubation and MV increase over time. As regards table (2) circulation of right and erroneous answers identified with information sub-things questions in 
regards to criteria requirement for mechanical ventilator uncovered that, the majority of the considered specimen have wrong replies in inquiries identified with criteria need for mechanical ventilator such as respiratory rate (RR) value. Indicators of arterial blood (ABG) needed to put the patient on $\mathrm{MV}$ and tidal volume (VT) value respectively.

This is in the line with Scotland, N. Q. I. (2007) $^{(23)}$ study on the effectiveness of nurses' knowledge on the patients outcomes which revealed that the majority of the CCNs' who participated in the study having low level knowledge and nonqualified in critical care nursing which need specialist knowledge required to care for the mechanical ventilated patient may lead to deterioration of the patient, failure of progression, and at worst increased mortality and morbidity . Also, The present study findings consistent with a study by (Eckerblad, Jeanette, et al., 2009) ${ }^{(24)}$ who conducted a study about knowledge and experience among $\mathrm{CCN}$ uncovered that most basic consideration medical attendants with various instructive levels, and years of experience or range of work had out of the blue inadmissible information scores about consideration of mechanical ventilated patients. It has been uncovered by a study that CCNs more often than not need information of the examination and confirmation with respect to mechanical ventilation. Also, another study by Martin J. Tobin ( 2001$)^{(19)}$ who conducted a study about skills among CCNs revealed that most of the medical caretakers in this part procure their insight into dealing with basically sick patients from their essential instructive projects, or from healing center arrangements and systems. Besides, the demographic profiles of the members additionally said that most of the medical attendants in the study gathering were confirmation holders, and temporary position attendants who had under 2 years of nursing knowledge.

This study discoveries also, consistent with Epstein, S. K. (2011) $)^{(25)}$ who conducted a study about qualification regarding mechanical ventilated patients among intensive care nurses on Evidencebased knowledge which revealed that the CCNs' knowledge results were poor.

Furthermore, another study by Kydonaki, K.(2011) ${ }^{(26)}$ who emphasized that the $\mathrm{CCN}$ science is that specially within nursing due to CCNs' deal specifically with human responses to lifethreatening innovative advances have happened, joined by a learning blast in basic consideration nursing. As advances have been made in pharmaceutical and innovation, tolerant consideration has turned out to be significantly more intricate, therefore, basic consideration medical attendants of that 21 st century are routinely looking after the complex, basically sick patient this is refined by coordinating modern innovation with the psychosocial challenges and moral clashes connected with basic ailment. Then again, new treatment modalities and innovation may contrarily influence the nature of consideration and positive result, though, they may create numerous difficulties to the basic consideration medical caretaker.
(Crocker,
C.
2009) $)^{(27)}$

demonstrated. That one of the noteworthy troubles that may defy the CCNs' is to be gifted both using a broad assortment of imaginative contraptions and meeting the patient needs. The utilization of mechanical ventilation (MV) in concentrated consideration join together (ICUs) is a key segment of the consideration of basically sick patients and a standout amongst the most usually utilized advancements as a part of basic consideration unit it might be required in 
CRITICAL CARE NURSES KNOWLEDGE AND PRACTICES etc...

more than $90 \%$ of fundamentally sick patients in ICUs.

Moreover, the researcher deciphered the reasons that lead to the absence of information with respect to criteria requirement for mechanical ventilator because of need in learning of the field is produced by essential nursing instruction, basic consideration nursing training, and basic consideration experience. Furthermore, shortage of nursing staff in intensive care units, lack of income, psychological and economical problems for CCNs' which reflect negatively on the care and outcomes of patient mechanical ventilated.

As regard table (3) for dispersion of right and off base answers identified with learning sub-things questions concerning weaning from mechanical ventilation shows that the majority of studied nurses' have got (incorrect) answers regarding weaning from mechanical ventilation as the Rapid Shallow Breathing Index (RSBI) value in the first of Spontaneous Breathing Trial (SBT). The Continuous Positive Airway Pressure (CPAP) value in the advance stage of Spontaneous Breathing Trial (SBT) and the time of weaning process respectively.

The findings supported by Nava \& Hill $\mathbf{( 2 0 0 9 )}^{(28)}$ who carried out of research about mechanical ventilator weaning with regards to basic consideration nursing and they uncovered that, the competency of the attendant increments when the doctor knows the medical attendant, and went ahead to clarify that medical caretakers' competency ought not be picked up forever through instruction (formal capabilities), but rather ought to be enhanced (casually) at the watchfulness of the individual doctor. This, be that as it may, would just apply to verbal requests, as composed requests took after the patient, not the medical caretaker. A few doctors expressed that weaning was encouraged when the doctor knew the medical attendant, and one doctor said: "I am not anxious of giving a request [for ventilator changes] when I know the medical caretaker". Once more, it was more critical for the doctor to know the medical attendant actually, than to depend upon the formal capabilities of the medical caretaker. Also, findings of current study supported by Blackwood, Bronagh, et al.,(2013) ${ }^{(29)}$ who reported that medical caretakers with the fitting knowledge can effectively participate in weaning process, frequently under the heading of intensives. Since medical caretakers have an abnormal state of contact with patients, they are in a perfect position to build up a restorative compatibility with patients, which can help in deciding when it is fitting to start weaning. Therefore, appropriate preparation of CCNs is a vital component in providing quality care to mechanical ventilation patients.

Moreover Epstein, S. K. (2011) ${ }^{(25)}$ revealed that the CCNs can't rehearse what they don't have the foggiest idea. Subsequently, giving consideration to mechanical ventilation patients need training to understudy medical attendants is indispensable, so that, they are set up to evaluate and deal with the complexities required being taken care of by the mechanical ventilation patients once they graduate to enhance the consideration of the mechanical ventilation patients. Along these lines, CCNs must have the information and the devices to viably give consideration to people genuine/life undermining diseases.

These findings are consistent with Eckerblad, Jeanette, et al., (2009) ${ }^{(24)}$ studies which focused on CCNs' role in MVW in a national overview in Sweden of weaning from mechanical ventilation demonstrates that basic consideration attendants are in a one of a kind position for adjusting a comprehensive way to deal with weaning, and the study distinguishes 
various quantifiable parameters which enhance the nature of consideration. An Australian overview of clinical basic leadership has demonstrated that basic consideration nurture once in a while adjust the patients' mechanical ventilation autonomously with a specific end goal to address the issues of their patients. In spite of the fact that medical attendants take an interest in basic leadership, there is a high level of variability in attendants' support, as it is found that choice frequencies are connected to medical caretakers' basic consideration experience, arrangement level, and nursing shifts.

Part II: Critical care nurses' practices regarding weaning of patients from mechanical ventilation about The second stated research question was : what is the level of practices that the critical care nurses' have regarding weaning of patients from mechanical ventilation:

In relation table (1) of nurses' practices regarding (Ventilator Parameters): Shows that most of the studied nurses didn't explain procedure to patient and assess minute volume (VE $120 \mathrm{ml} / \mathrm{kg}$ ) and assess respiratory rate ( $\mathrm{RR} 10-15 \mathrm{~b} / \mathrm{m}$ ) respectively.

Kevin T. Martin, (2009) (17) who conducted a study about lack of consistent ventilator monitoring which revealed that, the majority of the CCNs who participated in the study, can predispose the mechanically ventilated patients to numerous risks. Conversely, consistent monitoring of ventilator parameters has several advantages.

MacIntyre, N. R. (2013) $)^{(30)}$ who reported that patient-ventilator checking is viewed as essential amid MV because of the potential for fast and capricious changes in a patient's condition coming about because of the hidden disease, treatment modalities, and/or ventilator capacity. In particular, the reason for checking in this patient populace is fourfold: foundation of standard estimations from which the underlying treatment arrangement is inferred; distinguishing proof of patterns demonstrative of change or crumbling; directing choices to include, adjust, or cease treatment arrangements; and, assurance of suitable ventilator alert breaking points to defend a patient's wellbeing.

Also, Botha, L. (2012) ${ }^{(31)}$ who carry out study in ICUs in South Africa founded only $25 \%$ of nurses in the ICUS units in S.A. held an ICU qualification regard care patient mechanical ventilation and monitoring of ventilator parameters and noticed that medical caretakers did not appear to routinely apply hypothetical learning practically speaking that outcome poor practice that attendants may not comprehend the method of reasoning for utilizing particular mediations due to deficiencies in information about the physiology, brain research and humanism of mechanical ventilation. Along these lines, this may have antagonistically influenced their practice.

Hancock et al (2006) ${ }^{(32)}$ argue that at least $75 \%$ of nurses in the ICU should be ICU qualified to ensure optimal care of the patient. It is recommended that the mechanically ventilated patient be cared for by an ICU qualified nurse, as it is assumed that the ICU qualified nurse comes to the bedside with superior education and training, beyond the basic preparation required to qualify as a registered nurse and includes an understanding of the modes and monitoring required of the mechanically ventilated patient, thus contributing to optimal outcomes of the patient.

Also, the current study consisted with Cooper, N., Forrest, K., \& Cramp, P. (2008) ${ }^{(33)}$ who Mentioned that the competent nurse should be able to interpret and act upon the monitoring information displayed by the ventilator in terms of the clinical manifestations of the patient, also emphasized that $50 \%$ of the 
CRITICAL CARE NURSES KNOWLEDGE AND PRACTICES etc...

nurses should be founded in the ICU as qualified in interventions concern mechanical ventilator patient based on high levels of experience and knowledge and it was expected that these nurses would achieve the competency indicator of $75 \%$ by virtue of their training background and experience in the ICU.

So, the current study findings supported with Kevin T. Martin, (2009) (17) who demonstrated that the ventilator parameters monitored by the majority of critical care nurses were only mode of $\mathrm{MV}$ and $\mathrm{Fio}_{2}$ which were monitored once per shift. Therefore, the results of many studies suggesting that medical attendants watching over patients getting MV ought to evaluate the patient-ventilator framework at the every four hours.

Furthermore, Esteban, Andrés, et al., (2008) $^{(34)}$ suggested that the recurrence of patient-ventilator framework checks ought to be guided by the seriousness of a patient's condition. While the MacIntyre, N. R. $\left(\mathbf{2 0 1 3}^{(30)}\right)$ proposes that such checks be done after any adjustment in ventilator settings, at whatever point ventilator execution is being referred to, and as quickly as time permits after an intense crumbling of the patient's condition . MacIntyre, N. R. (2013) ${ }^{(30)}$ likewise propose that the base time between patient-ventilator framework checks ought not surpass six hours.

Moreover, a study uncovered the deficiency of medical attendants and overwhelming workloads connected with tending to basically sick patients may restrict the time given to the communication amongst patients and attendants for satisfactory mechanical ventilation appraise. Therefore, CCNs should be trained in the knowledge and skills required to preserve and maintain excellent practice regarding care of patient mechanical ventilation.

As regard to table (2) of nurses' practices concerning general conditions (readiness for weaning ): Shows the most of the studied subject didn't explain procedure to the patient. Discuss the assessment of findings and weaning parameters . Obtain base lines vital signs. Plan to initiate early weaning process in the day and document the patient responses or not to the weaning process. respectively .

The multifaceted nature of present day ICUs and the patients they serve. Alongside the raising expenses with giving concentrated consideration, have been variables spurring basic consideration doctors and medical attendants to distinguish and execute "best" clinical practices in their ICUs (Lanken\& Hanson 2013) $^{(35)}$

The consideration of the mechanically ventilated patient is at the center of a basic consideration clinical practice and weaning patients from mechanical ventilatory bolster remains a noteworthy testfor critical care nurses (Tobin, M. J., Laghi, F., \& Jubran, A. 2012 ) ${ }^{(19)}$

The move to unsupported breathing is frequently intricate procedure, requiring gifted evaluation and arranging by a multidisciplinary group. In this way, the utilization of a synergistic methodology, in which basic leadership is shared among individuals, appears a coherent administration procedure (Crocker, C., \& Kinnear, W. 2008) $)^{(27) .}$

In the previous decade, basic consideration attendants have seen an expanded enthusiasm for enhancing results for patients being weaned from mechanical ventilation and there has been a surge of enthusiasm for the of conventions and rules in clinical practice and wellbeing approach (Bristle, et al., 2014) ${ }^{(36)}$ it is important that CCNs' contribute to the development of such protocols and guidelines in order to actively shape their own practice (Eskandar, N., \& Apostolakos, M. J. $2007)^{(37)}$ 
Several studiesby Tobin, M. J., Laghi, F., \& Jubran, A.(2012) ${ }^{19)}$ accentuated the part of basic consideration in the administration of fundamentally sick patients amid weaning from MV and they reported that nursing consideration is a vital angle amid weaning process .

Unfortunately, the current study reveals unsatisfactory nursing practices during weaning process and general nursing management for the mechanically ventilated patient. It was found that the intended ICU settings have no formalized nursing guidelines or protocols kept in place for the management of artificially ventilated patients and weaning.

As regards general nursing practices performed in pre-weaning phase, the study findings revealed that the majority of nursing staff measured vital signs every hour. These results are in agreement with the (Frakes MA , 2001). Study and guidelines for patients on MV which recommend that imperative sings ought to be measured and recorded each hour until the patient is steady.

The critical care nurse in the present study documented nursing data in the nursing notes which are separate from the restorative record. This is tricky for a patient who require progressing evaluation and administration by a multidisciplinary group. Another issue is that the expected ICUs stream sheet offers just a snapshot (12-24 hours) of the patient's condition. This technique for documentation might be suitable for transient administration of patients, however it is lacking when long haul appraisal send arranging are required recommend that imperative sings ought to be measured and recorded each hour until the patient is steady, such as, in weaning from MV. New structures that support long-term decision making and communication between nursing and medical staff are needed to be used in the intended ICUs to promote collaborative decision making and facilitate the complex procedure of weaning .

Contrary to the conclusions of the current study (Rose, L., et al., 2008) $)^{(38)}$ found that theAustralian basic consideration medical caretaker had an abnormal state of duty, and self-rule in the administration of $\mathrm{MV}$ and weaning. Moreover, Blackwood, Bronagh, et al ., (2013) found that the basic consideration attendants are in charge of the continuous assessment and care of patients undergoing ventilator support and are becoming frequently more involved in the weaning process.

Regarding nursing practices during weaning process, the data of the present study demonstrated that the larger part of critical care nurses in the intended ICUs did not participate in weaning process either in assessment or in the development of weaning plan with the medical staff. Generally they did not share in decision making during weaning process. This may result from lack of knowledge, lack of self considers of critical care nurses or lack of support from medical staff who decision making associated with MV and weaning is the obligation of therapeutic staff and the basic consideration medical attendant has not particular part in this procedure.

Furthermore, the results of the present study demonstrated that the greater part of nursing staff did not prepare the patient efficiently before weaning trial which may negatively affect weaning outcome. Therefore, the importance of nursing decision making in weaning process was highlighted by (Elhabashy, S. 2015) ${ }^{(39)}$ who reported that basic consideration medical caretakers enhance weaning results and lessen the span of mechanical ventilation.

Moreover, The present study has shown that weaning is an escalated innovation, which includes prompt proportional coordination amongst medical attendant and doctor. Mechanical ventilator 
CRITICAL CARE NURSES KNOWLEDGE AND PRACTICES etc...

weaning does not include successive errand association, where medical attendants must sit tight for guidelines from the doctors before they act, and doctors once in a while demonstration without illuminating the medical attendants. It has been watched that doctors once in a while control the ventilator autonomously, in light of the fact that it is risky for the patient if the medical attendant doesn't know about changes. At the point when medical caretakers control the ventilator, they for the most part illuminate the doctor quickly some time recently, or at the earliest opportunity after the movement. Also, The present study has demonstrated that collaboration, past the range of an eight hour shift, does not exist at the site in the study. This implies data must go through an incredible number of individuals and that some data might be misconstrued or lost.

So, examines have proposed that methodical weaning, for example, the utilization of multidisciplinary weaning groups, result in enhanced expense and quality results for patients requiring delayed mechanical ventilation (Blackwood, Bronagh, et al ., 2013) ${ }^{(29)}$. The perfect circumstance for weaning, as a dynamic serious innovation, is to guarantee staff coherence which empowers collaboration. The destinations in the present study had an ungraceful way to deal with weaning. They didn't utilize formal weaning groups and the objectives and techniques for weaning were enunciated vaguely. Absence of cooperation was exhibited as a low level of nonstop and combined staffunderstanding coherence, combined with the way that the same attendant and doctor seldom directed rounds on the same patient more than once amid a direction. The staffing design in the present study was not helpful for a methodical way to deal with weaning.
Conclusion:

Based on the findings of the current study, it can be concluded that:

- Critical care nurses had inadequate knowledge and practices score regarding weaning of patients from mechanical ventilation.

- Nurses with a higher educational level had better knowledge score than nurses with low educational level.

- Increased years of experience had a positive effect on nurses' practices regarding $r$ weaning of patients from mechanical ventilation.

- There was no significant statistical correlation between the total score of knowledge and total score of practices of the studied nurse.

\section{Recommendations:}

Based on findings of the present study, the following recommendations were made:

- Provide nurses with continuous educational programs with evidence based guidelines to improve their knowledge and practices regarding weaning of patients from mechanical ventilation.

- Follow up nurses' practices in relation mechanical ventilation weaning.

- Provide nurses with periodic sessions to improve their practices regarding weaning of patients from mechanical ventilation.

- Establish collaborative interaction between nurses and other health team members as they are working in a multi-disciplinary system to improve the health services provided to patients with mechanical ventilation .

- Mechanical ventilation weaning should be included partially in the patient's assessment sheet.

- Minimize the number of patients for each nurse to be (nurse: patient) ratio not more $(1: 2)$ to decrease nurses' workloads. 
Support critical care units with printed universal guidelines illustrated simple in posters and booklets related to Mechanical ventilation weaning.

- Handling of barriers to mechanical ventilation weaning application among critically ill patients.

- Replication of the study on a larger probability sample from different geographical areas in Egypt.?

\section{References}

1. Irici, Emine; Can, Mehmet Fatih; Yildiz, Ramazan. , (2016) Weaning From Mechanical Ventilation Driven By Non-Physician Professionals Versus Physicians. International Journal Of Caring Sciences;9 (1): 274.

2. Banner, M. J., Euliano, N. R., Martin, A. D., Al-Rawas, N., Layon, A. J., \& Gabrielli, A. (2012). Noninvasive work of breathing improves prediction of post-extubation outcome. Intensive care medicine, 38(2), 248-255.

3. Blackwood, B., Murray, M., Chisakuta, A., Cardwell, C. R., \& O'Halloran, P. (2013). Protocolized versus non-protocolized weaning for reducing the duration of invasive mechanical ventilation in critically ill paediatric patients. The Cochrane Library.

4. Boles, J. M., Bion, J., Connors, A., Herridge, M., Marsh, B., Melot, C., \& Welte, T. (2007)Weaning from mechanical ventilation. European Respiratory Journal ; 29(5) : 1033 1056.

5. Boles, J. M., Bion, J., Connors, A., Herridge, M., Marsh, B., Melot, C., \& Welte, T.( 2009) Weaning from mechanical ventilation. European Respiratory Journal; 29(5):1033-1056.
6. Botha, lynn.( 2012). Level of nurses 'competence in mechanical ventilation in intensive care units of two tertiary health care institutions in Gauteng. Diss. Faculty of community and health sciences, department of nursing education, university of the witwatersrand Johannesburg,

7. Bristle, T. J., Collins, S., Hewer, I., \& Hollifield, K. .( 2014) Anesthesia and critical care ventilator modes: past, present, and future. AANA journal; 82(5).

8. Cooper, Nicola, Kirsty Forrest, and Paul Cramp. .( 2008) Essential guide to acute care. John Wiley \& Sons,.

9. Crocker, Cheryl, and William Kinnear.( 2008). "Weaning from ventilation: Does a care bundle approach work?." Intensive and Critical Care Nursing; 24(3): 180-186.

10. De Prost, N., Ricard, J. D., Saumon, G., \& Dreyfuss, D. .( 2011) , Ventilator-induced lung injury: historical perspectives and clinical implications. Annals of intensive care; 1(1): 1 .

11. Eckerblad, J., Eriksson, H., Kärner, A., \& Edéll-Gustafsson, .( 2009) U. Nurses' conceptions of facilitative strategies of weaning patients from mechanical ventilation-a phenomenographic study. Intensive and Critical Care Nursing; 25(5): 225232.

12. Elhabashy, Sameh. ( 2015) CardioThoracic Injury, Essentials All Critical Care Nurses Need To Know. Lulu. com, 2015.

13. Epstein, Scott K ( 2011). "How often does patient-ventilator asynchrony occur and what are the 
CRITICAL CARE NURSES KNOWLEDGE AND PRACTICES etc...

consequences?." Respiratory care; 56: 25-38.

14. Eskandar, Nizar, and Michael J. Apostolakos( 2007) . "Weaning from mechanical ventilation." Critical care clinics 2007; 23 (2): 263-274.

15. Esteban, A., Ferguson, N. D., Meade, M. O., Frutos-Vivar, F., Apezteguia, C., Brochard, L., .\& González, M. (2008). Evolution of mechanical ventilation in response to clinical research. American journal of respiratory and critical care medicine, 177(2), 170-177.

16. Girard, T. D., Kress, J. P., Fuchs, B. D., Thomason, J. W., Schweickert, W. D., Pun, B. T., ... \& Jackson, J. C. (2008). Efficacy and safety of a paired sedation and ventilator weaning protocol for mechanically ventilated patients in intensive care (Awakening and Breathing Controlled trial): a randomised controlled trial. The Lancet; 371(9607):126-134.

\section{Hancock, Helen C; Easen, Patrick}

R. (2008). The decision-making processes of nurses when extubating patients following cardiac surgery: an ethnographic study. International journal of nursing studies; 2006 43(6): 693-705.

\section{Hancock, Helen C; Easen, Patrick}

R. (2008). The decision-making processes of nurses when extubating patients following cardiac surgery: an ethnographic study. International journal of nursing studies; 43(6): 693705.

19. Hansen, Britt Sætre; Severinsson, Elisabeth. (2007). Intensive care nurses' perceptions of protocoldirected weaning - a qualitative study.
Intensive and Critical Care Nursing,;23(4): 196-205.

20. Kydonaki, Kalliopi(2011).

Decision-Making Processes Of

Weaning From Mechanical

Ventilation: A Comparative

Ethnographic Insight Into The

Dynamics Of The Decision-Making

Environment. 2011.

21. Lanken, P. N., Manaker, S., Kohl,

B. A., \& Hanson III, C. W(2013). Intensive care unit manual. Elsevier Health Sciences.

22. Macintyre, Neil R. (2013). The ventilator discontinuation process: an expanding evidence base. Respiratory care, 2013; 58 (6): 1074-1086.

23. Martin J. Tobin, M.D. (2001). Advances in Mechanical Ventilation, N Engl J Med; 344.

24. Millar, A. B., Leach, R., Preston, R., Lim, W. S., Breen, R., Higgins, B., \& Harvey, J. (2014). Respiratory diseases and respiratory failure. Oxford Desk Reference: Acute Medicine, 147.

25. Morton, P. G., Fontaine, D. K., Hudak, C. M., \& Gallo, B. M (2015).Critical care nursing: a holistic approach . 2015. (Vol. 1). Philadelphia: Lippincott Williams \& Wilkins.

26. Nava, Stefano, and Nicholas Hill. (2009). "Non-invasive ventilation in acute respiratory failure." The Lancet.; 374: 250-259.

27. Rose, Michael R., and Patrick Gordon. (2014). "Muscle Pain and Fatigue." Evaluation and Treatment of Myopathies ; 87.

28. Salam, A., Tilluckdharry, L., Amoateng-Adjepong, Y., \& 
Manthous, C. A. (2004). Neurologic status, cough, secretions and extubation outcomes. Intensive care medicine, 2004; 30(7):1334-1339.

29. Scotland, NHS Quality Improvement. (2007). "Caring for the Patient with a Tracheostomy." Edinburgh. NHS Quality Improvement Scotland. NICE Head Injury, Triage Assessment, Investigation and Early Management of Head Injury in Infants, Children and Adults-Clinical Guideline; 4: 4651.

30. Tobin, Martin J., Amal Jubran, and Franco Laghi. (2001). "Patientventilator interaction." American journal of respiratory and critical care medicine. 2001; 163(5): 1059-1063.
31. Tobin, Martin J., Franco Laghi, and Amal Jubran. (2012). "Ventilatory failure, ventilator support, and ventilator weaning." Comprehensive Physiology.

32. Wheeler, Arthur P.; Bernard, Gordon R. (2007). Acute lung injury and the acute respiratory distress syndrome: a clinical review. The Lancet; 369 (9572) : 1553-1564.

33. Kevin T. Martin (2009)..weaning from mechanical ventilation. 